\title{
Microstructure Evaluation of Friction Stir Welded AZ91 with CaO Mg Alloy
}

\author{
Don Hyun Choi ${ }^{1, * 1}$, Byung Wook Ahn ${ }^{1}$, Shae Kwang Kim² ${ }^{2}$ Yun Mo Yeon ${ }^{3}$, \\ Young Jik Kim ${ }^{1}$, Sun-Kyu Park ${ }^{4}$ and Seung Boo Jung ${ }^{1, * 2}$ \\ ${ }^{1}$ School of Advanced Materials Science and Engineering, Sungkyunkwan University, \\ 300 Cheoncheon-dong, Jangan-gu, Gyeonggi-do 440-746, Korea \\ ${ }^{2}$ Korea Institute of Industrial Technology, 7-47 Songdo-dong, Yeonsu-gu, Incheon 406-840, Korea \\ ${ }^{3}$ Department of Advanced Materials Application, Suwon Science College, \\ 9-10 Botong-li, Jeongnam-myeon, Whasung, Gyeonggi-do 445-745, Korea \\ ${ }^{4}$ School of Civil and Environmental Engineering, Sungkyunkwan University, \\ 300 Cheoncheon-dong, Jangan-gu, Gyeonggi-do 440-746, Korea
}

\begin{abstract}
The present study was carried out to evaluate the microstructural properties of a friction stir welded AZ91 with CaO Mg alloy. For this work, friction stir welding (FSW) was performed at a tool rotation speed of $1250 \mathrm{rpm}$ and a traveling speed of $32 \mathrm{~mm} \cdot \mathrm{min}^{-1}$. A network of intermetallic compounds $\left(\mathrm{Al}_{2} \mathrm{Ca}\right)$ was observed in the base metal (BM). In the stir zone (SZ), fine grains and intermetallic compound particles were formed due to dynamic recrystalization and mechanical stirring. The hardness profile showed that the hardness of the SZ was higher than that of the BM, probably due to the presence of fine grains and thermally stable intermetallic compounds. [doi:10.2320/matertrans.M2010271]
\end{abstract}

(Received August 11, 2010; Accepted January 6, 2011; Published April 1, 2011)

Keywords: friction stir welding, AZ91, CaO, hardness, thermal stability

\section{Introduction}

In recent years, vehicle weight reduction has been an important issue in the automotive industry, due to the necessity to reduce fuel consumption and global warming. ${ }^{1)}$ The demand for $\mathrm{Mg}$ alloys has increased, due to their low density and good specific mechanical properties. With their increasing application in industry, it is necessary to develop effective welding techniques for the joining of $\mathrm{Mg}$ alloys. However, the fusion welding of these materials is difficult, due to the formation of vast porosity. ${ }^{2)}$ Friction stir welding (FSW), a novel solid joining technology, is a potential candidate, because of its many advantages compared with the traditional fusion welding processes. It can produce pore-free joints where the pores caused by casting solidification are eliminated, and fine-grained structures are generated in the joint where dynamic recrystallization occurs. ${ }^{3)}$ In previous studies, the FSW of Mg alloy was mainly focused on die-cast and extruded AZ alloys and AM alloys. ${ }^{4-11)}$ However, there has been little research into heat resistant $\mathrm{Mg}$ alloys, ${ }^{12}$ ) whose creep resistance is superior due to the existence of intermetallic compounds at the grain boundaries. In the present work, AZ91 with $\mathrm{CaO}^{13)}$ was friction stir welded and the microstructural properties after FSW were extensively investigated.

\section{Experimental Procedure}

The butt-welding of AZ91 with $\mathrm{CaO}$ (9.1 mass\%Al0.64 mass $\% \mathrm{Zn}-0.01$ mass $\% \mathrm{Ca}-0.3$ mass\% $\mathrm{CaO}, \mathrm{Mg}$ Bal.) was performed by FSW. Mg alloy plates were machined to a size of $70 \mathrm{~mm} \times 140 \mathrm{~mm} \times 4 \mathrm{~mm}$ for welding. The tool rotation speed and travel speed were fixed at $1250 \mathrm{rpm}$ and

\footnotetext{
${ }^{* 1}$ Graduate Student, Sungkyunkwan University

*2 Corresponding author, E-mail: sbjung@skku.edu
}

$32 \mathrm{~mm} \cdot \mathrm{min}^{-1}$, respectively. After FSW, the cross-sectional specimens were cut perpendicular to the welding direction, mechanically ground with abrasive paper, and polished with 1 and $0.3 \mu \mathrm{m}$ alumina powders. Optical microscopy (OM) and electron probe micro analysis (EPMA) observations were carried out for the weld. And X-ray diffraction was used to phase analysis. The Vickers hardness profile of the weld was measured on the cross-section perpendicular to the welding direction.

\section{Result and Discussion}

Figure 1(a) shows an overview of the cross-section of joint, and the microstructure in the base metal (BM), thermomechanically affected zone (TMAZ) and stir zone (SZ) are shown in Figs. 1(b)-(d), respectively. The BM exhibits a typical solidification microstructure formed in the casting process. The grains in the TMAZ were greatly deformed due to the friction heat and mechanical deformation, and the grains have an obvious orientation along the metal-flow direction induced by stirring. The SZ contains fine recrystallized grains instead of dendritic ones, and the intermetallic compound (dark phase in Fig. 1) seems to be uniformly dispersed in the SZ.

Figure 2 shows the result of the EPMA analysis of the BM, TMAZ, and SZ. The microstructure of the BM, which is shown in Fig. 2(a), is mainly composed of $\alpha$-Mg grains and a network of intermetallic compounds along the grain boundaries. And it shows that the concentrations of $\mathrm{Al}$ and $\mathrm{Ca}$ in the network structure are much higher than those in the $\alpha-\mathrm{Mg}$ grains. The TMAZ (Fig. 2(b)), where both thermal and plastic deformation effects were evident, is composed of Al$\mathrm{Ca}$ intermetallic compounds and recrystallized grains, and the former have an obvious orientation along the metal-flow direction induced by stirring. In the SZ (Fig. 2(c)), the original cast structure of the BM changed to a fine recrystal- 

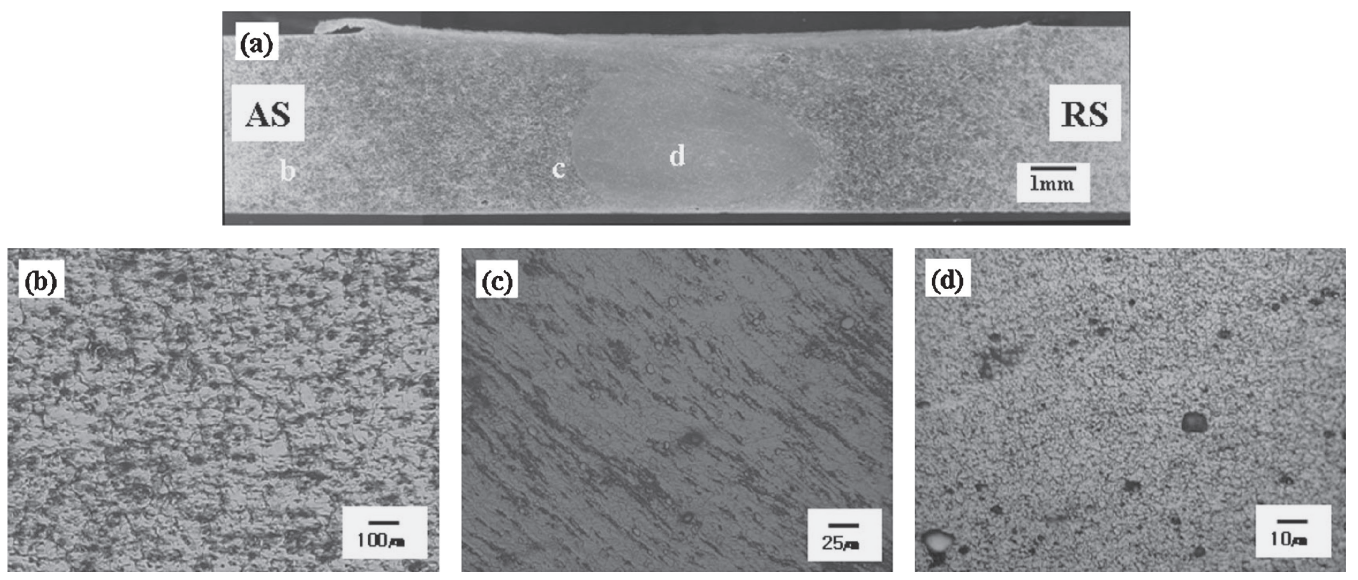

Fig. 1 Each microstructures in the joint produced by friction stir welding: (a) Macro cross-section of weld nugget, (b) BM, (c) TMAZ, (d) SZ.

lized grain structure, and fine Al-Ca intermetallic compound particles were homogeneously distributed in the $\alpha-\mathrm{Mg}$ matrix due to plastic deformation and stirring. It is worth noting that the intermetallic compounds existed in all three zones, i.e., the BM, TMAZ and SZ, although their shape and size differed.

For the correctly phase analysis, XRD analysis was carried out and its result is shown in Fig. 3. In case of BM (Fig. 3(a)), the matrix consisted with primarily of $\alpha-\mathrm{Mg}$ as major phase and $\mathrm{Al}_{2} \mathrm{Ca}$ as minor phase. Also in the $\mathrm{SZ}$, as shown in Fig. 3(b), SZ has also $\alpha-\mathrm{Mg}$ and $\mathrm{Al}_{2} \mathrm{Ca}$ phases. Considering these results, it is suggested that the main network compound is $\mathrm{Al}_{2} \mathrm{Ca}$ and it is quite stable at this processing temperature.

However, $\mathrm{CaO}$ was not observed in these materials; the $\mathrm{CaO}$ particles that were initially added were gone and, instead, $\mathrm{Al}_{2} \mathrm{Ca}$ intermetallic compounds were observed over the $\mathrm{Mg}$ matrix. At the casting temperature of $953 \mathrm{~K}$, the standard free energy change, $\Delta G_{\mathrm{o}}$ of reaction of $\mathrm{Mg}(\mathrm{l})+$ $2 \mathrm{Al}(\mathrm{l})+\mathrm{CaO}(\mathrm{s})=\mathrm{Al}_{2} \mathrm{Ca}(\mathrm{s})+\mathrm{MgO}(\mathrm{s})$ was $-9 \mathrm{~kJ}$, indicating that the forward reaction could occur spontaneously. ${ }^{14)}$

Matsumoto et al. studied the influence of heat treatment on the microstructure of the as-thixomoulded $\mathrm{Mg}-6$ mass\% $\mathrm{Al}-$ 3 mass $\%$ Ca material. It was shown that although the partial dissolution of the intermetallic compounds took place, most of the network structure was retained after being heated at $623 \mathrm{~K}$ for $1 \mathrm{~h} .{ }^{12)}$ And $\mathrm{F}$. Islam reported that $\left(\mathrm{L} \leftrightarrow \mathrm{Al}_{2} \mathrm{Ca}+\right.$ $\mathrm{Mg}$ ) reaction temperatures were $773.88 \mathrm{~K} \sim 815.00 \mathrm{~K}$ in $\mathrm{Mg}$ Al-Ca ternary system. ${ }^{15)}$ Also, it was reported that critical temperature of AZ61 was $593 \mathrm{~K}$ during friction stir welding. ${ }^{3)}$ From these result, it suggested that dissolution and reprecipitation of $\mathrm{Al}_{2} \mathrm{Ca}$ intermetallic compound could not be the main reasons for the change in the intermetallic compound morphology, because the thermal condition is not sufficient for this mechanism. Rather the size and shape of the intermetallic compounds were changed mainly through mechanical fracture. It has been reported by many researchers that the microstructure of $\mathrm{Mg}$ alloys can be refined through FSW, since dynamic recrystalization occurs in the $\mathrm{SZ}$ during welding. The size of the $\mathrm{Mg}$ grains in the SZ ranges from 2 to $25 \mu \mathrm{m}$, depending on the chemical composition and welding parameters. ${ }^{6-11)}$ In this research, a relatively fine grain structure with an average size of $1 \sim 2 \mu \mathrm{m}$ was produced by FSW. This microstructure was somewhat similar to that of a metal matrix composite and different from the microstructure produced by the FSW of other Mg alloys whose base metals are composed of dual phases, viz. $\mathrm{Mg}$ grains and intermetallic compounds such as $\mathrm{Al}_{12} \mathrm{Mg}_{17}$. After FSW, the microstructures of the SZ, consisting almost entirely of dynamically recrystallized $\mathrm{Mg}$ grains and intermetallic compounds, tend to disappear, due to their dissolution at elevated temperature. As regards the present material, both the BM and SZ were composed of two phases, viz. $\mathrm{Mg}$ grains and intermetallic compounds such as $\mathrm{Al}_{2} \mathrm{Ca}$. The main reason for the formation of this microstructure is the thermal stability of second phases such as $\mathrm{Al}_{2} \mathrm{Ca}$. Considering the $\mathrm{Mg}$-Al binary phase diagram, the $\mathrm{Mg}_{17} \mathrm{Al}_{12}$ intermetallic compounds in AZ91 completely dissolve into the $\mathrm{Mg}$ matrix when the temperature is higher than $643 \mathrm{~K}$. Therefore, the peak temperature of the SZ in this study is high enough for the $\mathrm{Mg}_{17} \mathrm{Al}_{12}$ intermetallic compound in $\mathrm{AZ91}$ to dissolve into the matrix. However, as mentioned above, the $\mathrm{Al}_{2} \mathrm{Ca}$ intermetallic compound in this material is very stable at high temperature. Therefore, it seems that these particles hindered the grain growth after dynamic recrystallization due to the Zener pining effect. ${ }^{12}$ )

Considering these results, it is suggested that the microstructure of this material during FSW was different from that of the FSW joints of other $\mathrm{Mg}$ alloys, due to the existence of this heat stable $\mathrm{Al}_{2} \mathrm{Ca}$ intermetallic compound. Figure 4 shows the hardness profiles measured along the mid-thickness line of the cross section. It shows that the hardness of the SZ was higher than that of the BM; the average hardnesses of the SZ and BM were $65 \mathrm{HV}$ and $90 \mathrm{HV}$, respectively. We believe that the improvement in the hardness of the SZ is related to the grain size and presence of intermetallic compound particles. Firstly, the grains of the SZ were finer than those of the BM and it is well known that fine grains play an important role in strengthening the SZ. Secondly, the small intermetallic compound particles also contributed to increasing the hardness according to the dispersion strengthening mechanism. The hardness profile of the FSWed joint of the same AZ91 without $\mathrm{CaO}$ is also illustrated in Fig. 4. In this material, the average hardness of the SZ was slightly higher than that of the BM, but lower than that of the SZ in 

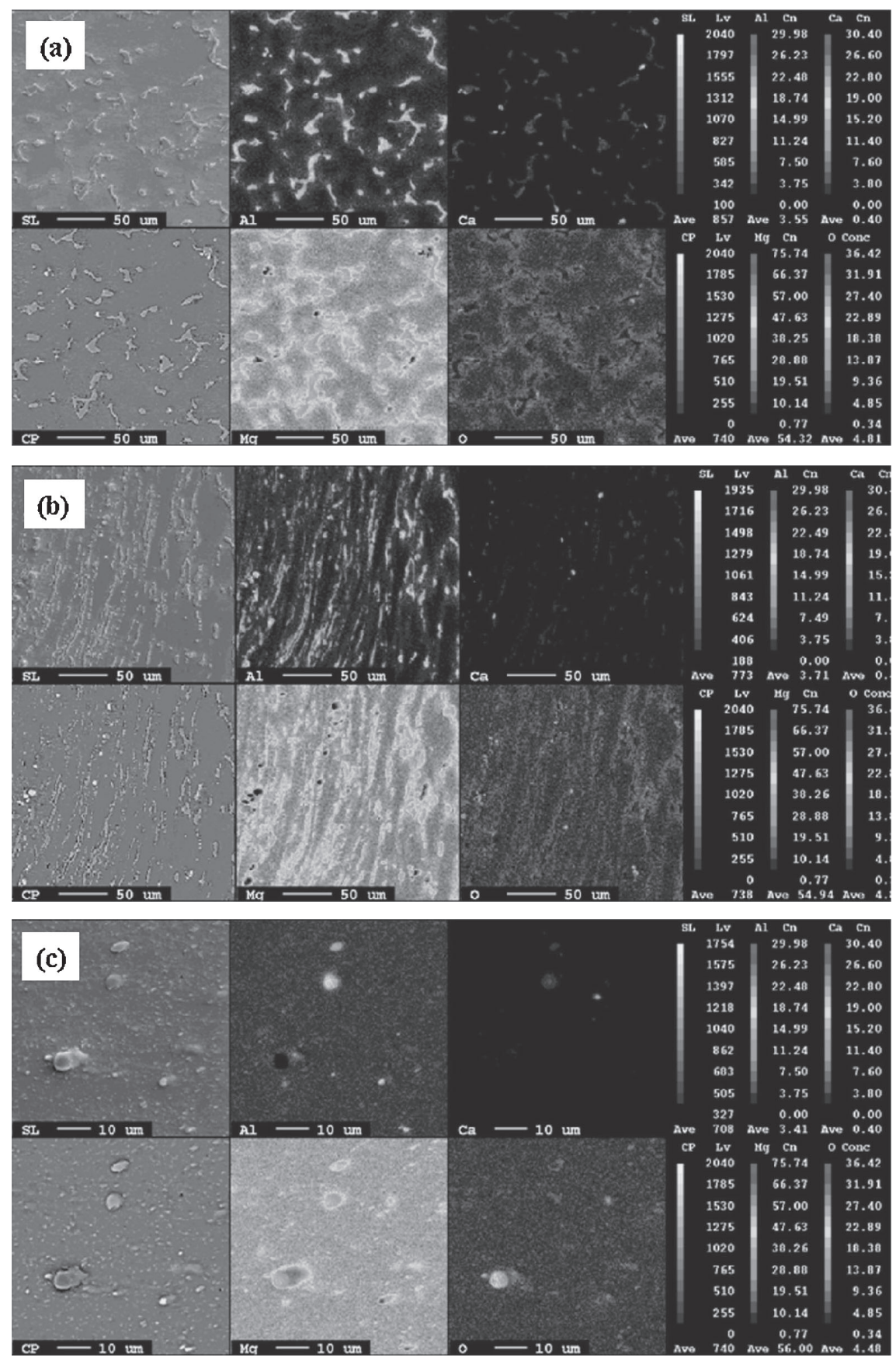

Fig. 2 Result of EPMA analysis in each region: (a) BM, (b) TMAZ, (c) SZ.
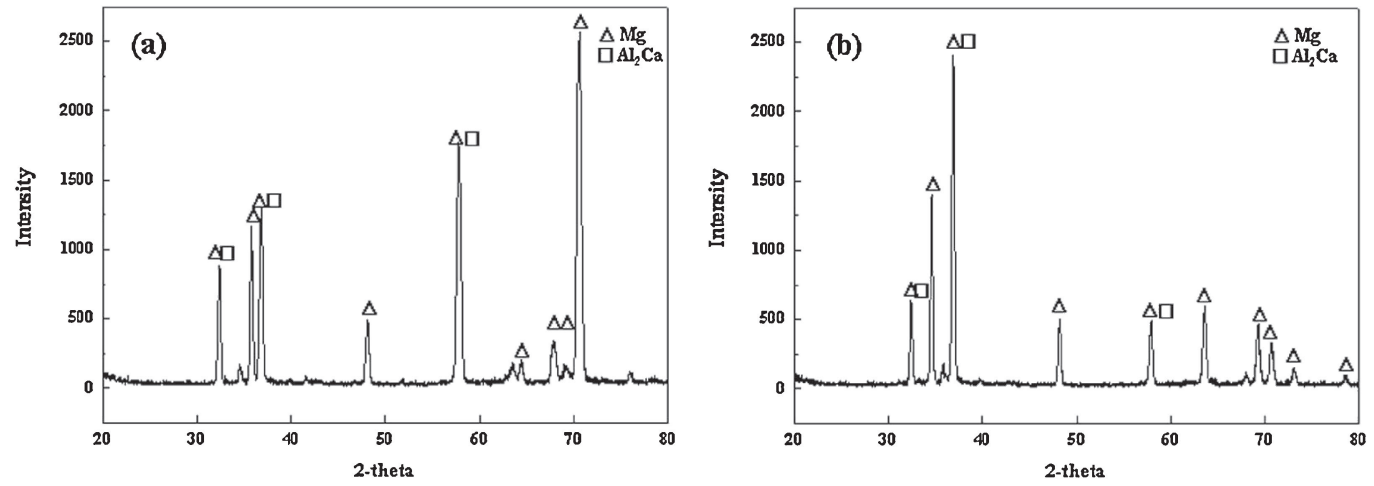

Fig. 3 XRD pattern of each region: (a) BM, (b) SZ. 


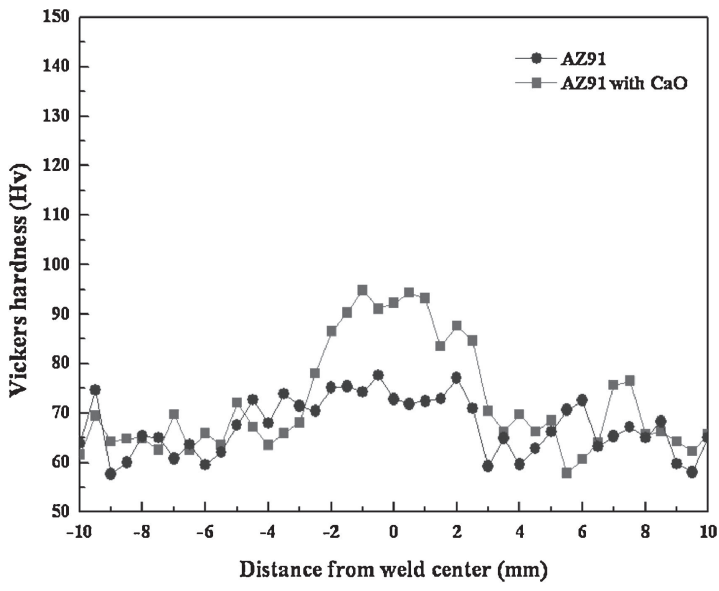

Fig. 4 Vickers hardness distributions of the welds of AZ91 and AZ91 with $\mathrm{CaO}$.

AZ91 with $\mathrm{CaO}$. We assumed that although the intermetallic compound $\left(\mathrm{Al}_{12} \mathrm{Mg}_{17}\right)$ dissolved due to friction heating, the fine grains contributed to increasing the hardness in the SZ. However, since the intermetallic compound $\left(\mathrm{Al}_{2} \mathrm{Ca}\right)$ in AZ91 with $\mathrm{CaO}$ is stable at high temperature and dispersed uniformly in the SZ, these dispersed small particles contributed to increasing the hardness in the SZ through the dispersion-strengthening mechanism.

\section{Conclusion}

The microstructure of AZ91 with $\mathrm{CaO}$ which was welded by friction stir welding, was investigated. Compared with the $\mathrm{BM}$, very fine grains were present in the SZ, due to dynamic recrystalization. The network of intermetallic compounds $\left(\mathrm{Al}_{2} \mathrm{Ca}\right)$ in the $\mathrm{BM}$ was changed to very small particles due to mechanical stirring. This increase in the hardness of the SZ was attributed to this stable intermetallic compound.

\section{Acknowledgment}

This work was supported by the WCU program of Korea Science \& Engineering Foundation funded by the Korean government (MOEHRD) (Grant No. R32-2008-000-10124-0).

\section{REFERENCES}

1) B. L. Mordike and T. Ebert: Mater. Sci. Eng. A 302 (2001) 37-45.

2) A. Weisheit, R. Galun and B. L. Mordike: Weld J. 77 (1998) 149s$154 \mathrm{~s}$.

3) S. H. C. Park, Y. S. Sato and H. Kokawa: Scr. Mater. 49 (2003) 161166.

4) J. A. Esparza, W. C. Davis and L. E. Murr: J. Mater. Sci. 38 (2003) 941-952.

5) C. Y. Lee, W. B. Lee, Y. M. Yeon and S. B. Jung: Mater. Sci. Forum 475-479 (2005) 555-558.

6) W. B. Lee, C. Y. Lee, M. K. Kim, J. I. Yoon, Y. J. Kim, Y. M. Yoen and S. B. Jung: Compos. Sci. Technol. 66 (2006) 1513-1520.

7) N. Afrin, D. L. Chen, X. Cao and M. Jahazi: Mater. Sci. Eng. A Struct. 472 (2008) 179-186.

8) L. Commin, M. Dumont, J. E. Masse and L. Barrallier: Acta Mater. 57 (2009) 326-334.

9) C. Y. Lee, W. B. Lee, Y. M. Yeon and S. B. Jung: Mater. Sci. 486-487 (2005) 249-252.

10) M. A. Gharacheh, A. H. Kokabi, G. H. Daneshi, B. Shalchi Amirkhiz and R. Sarrafi: Int. J. Mach. Tool. Manu. 46 (2006) 1983-1987.

11) S. Lim, S. Kim, C. G. Lee, C. D. Yim and S. J. Kim: Metall. Mater. Trans. A 36A (2005) 1609-1612.

12) D. T. Zhang, M. Suzuki and K. Maruyama: Scr. Mater. 52 (2005) 899903.

13) S. K. Kim, Y. J. Kim, J. K. Lee, Y. O. Yoon and H. H. Cho: February 2005: Korea Patent No. 10-2005-0016143.

14) D. B. Lee, L. S. Hong and Y. J. Kim: Mater. Trans. 49 (2008) 10841088.

15) F. Islam and M. Medraj: Canaidan Metal. Quart. 44 (2005) 1-14. 